\title{
Reflexiones sobre una unión fracasada ${ }^{1}$
}

\author{
JOHN H. ELLIOTT \\ Oriel College, University of Oxford \\ Reflections about an Unsuccessful Union
}

\begin{abstract}
RESUMEN
En los últimos años hemos sido testigos de un cambio de tendencia con respecto al estado-nación como tema central de la historia política europea. Al mismo tiempo, hemos presenciado un creciente interés en las «monarquías compuestas» como entidades políticas importantes en la Europa de la Edad Moderna. La historiografía portuguesa, con un sólido énfasis en la historia de Portugal como nación independiente, se ha inclinado a considerar los años entre 1580 y 1640 como un desafortunado episodio dentro de la historia nacional, concentrándose especialmente en aquellos aspectos del período de la Unión de las Coronas que parecían presagiar la recuperación de la independencia, como si éste desenlace hubiese sido más o menos inevitable. El propósito de este artículo es el de equilibrar la balanza mediante el análisis de la naturaleza de la Unión y las consecuencias, tanto positivas como negativas, de la incorporación de Portugal a la Monarquía Hispánica, concluyendo con una disquisición especulativa sobre la supuesta inevitabilidad de la ruptura con la España de Felipe IV en 1640.
\end{abstract}

\footnotetext{
1 Traducción de Gonzalo Velasco Berenguer.
}

\begin{abstract}
Recent years have seen a move away from the tendency to make the rise of the nation state the central theme of European political history, and a growing interest in «composite monarchies» as important political entities in early modern Europe. Portuguese historiography, with its heavy emphasis on the history of Portugal as an independent nation, has tended to regard the years 1580-1640 as an unfortunate interlude in the national story, and has concentrated in particular on those aspects of the period of the Union of the Crowns which seem to look forward to the recovery of independence as a more or less inevitable development. This essay seeks to redress the balance by examining the nature of the Union and the consequences, positive as well as negative, of Portugal's incorporation into the Spanish Monarchy, and ends by speculating on the assumed inevitability of the break with the Spain of Philip IV in 1640 .
\end{abstract}




\section{PALABRAS CLAVE: KEY WORDS:}

Monarquía compuesta, Monarquía Hispánica, Unión, Provincia, Olivares, Brasil, Mercaderes, Conversos.
Composite monarchy, Spanish Monarchy, Union, Province, Olivares, Brazil, Merchants, Conversos.

Desde hace unos años hemos sido testigos de un replanteamiento fundamental de la historia del estado-nación en contraposición a cómo escribieron sobre ésta los historiadores del siglo XIX y de buena parte del XX, para quienes fue la culminación lógica de mil años de historia europea. Este proceso de replanteamiento ha tenido consecuencias especialmente importantes para nuestra comprensión de la historia política, administrativa y judicial de los entramados políticos de la Europa de los siglos dieciséis y diecisiete, que no siempre se movieron necesaria o inevitablemente en la misma dirección.

Viene al caso, como ejemplo de este revisionismo histórico, el interés actual en torno al fenómeno que ahora llamamos monarquía compuesta, que generaciones anteriores de historiadores tendieron a describir como anacrónica en una Europa que había tomado el camino inexorable hacia la uniformidad administrativa y la consecución de un sentimiento de identidad nacional. Términos que antes dábamos por supuestos, como «estado», «nación» o «imperio» están siendo analizados nuevamente y han sido considerados, en algunos aspectos, como poco apropiados para describir la, a menudo, poco ordenada realidad de la Europa moderna. Al mismo tiempo, el impacto que la globalización ha tenido en la generación actual de historiadores ha hecho a éstos poco pacientes ante narrativas históricas confinadas a unidades nacionales individuales y a entidades territoriales. Conscientes de la naturaleza porosa de fronteras y límites territoriales, han tratado de situar sus historias en contextos más amplios tanto a nivel transnacional como a nivel global. El movimiento y la conexión son características fundamentales de nuestro tiempo, y es por ello natural que estén adoptando un papel central en el marco de la escritura histórica contemporánea.

Estos avances historiográficos han ejercido, naturalmente, una gran influencia sobre la forma en la que pensamos acerca de la Monarquía Hispánica en la época de los Austrias. En el pasado y con demasiada frecuencia, la historia de España ha sido fagocitada por la historia de Castilla como la fuerza motriz que estaba detrás de la construcción de un estado y un imperio españoles. Al mismo tiempo, los historiadores de aquellos reinos y provincias que se encontraron sujetos a los mandatos de un gobierno distante situado en Madrid, eran susceptibles de centrarse en su propia historia regional o nacional, excluyendo así el contexto más amplio de la Monarquía de las que sus tierras natales formaban parte. De esta forma, tendían a percibir su historia en términos de explotación por parte del gobierno central y sus oficiales locales. Así, sus narrativas se convirtieron en narrativas victimistas y en relatos sobre la frustración temporal o 
permanente de sus aspiraciones nacionales y de su camino hacia la transformación de su tierra en estado.

En los últimos años, los historiadores han desarrollado un mayor interés por la compleja naturaleza de las relaciones entre política y sociedad en Castilla, corazón de la monarquía, y el funcionamiento del gobierno central de Madrid. Al mismo tiempo, parece que hay indicaciones de que se están produciendo cambios en las perspectivas históricas desde la periferia. Los italianos que estudian la Italia española, o los mejicanos que estudian el virreinato de la Nueva España ya no escriben automáticamente historias retrospectivas destinadas a recuperar aquellos aspectos del pasado que puedan considerarse presagios de la eventual consecución de la independencia nacional. Lo mismo puede decirse de los historiadores que estudian Portugal durante el período de la Unión de las Coronas, aunque es posible que sus conclusiones no hayan tenido un amplio nivel de difusión entre el público. Es difícil zafarse de narrativas nacionales tradicionales, transmitidas de generación en generación y constantemente alimentadas por regímenes sucesivos con el objetivo de construir o consolidar un sentimiento de identidad nacional.

Es posible que esta dificultad haya sido especialmente profunda en el caso de Portugal porque los sesenta años que duró la Unión representan un episodio muy breve en la larga historia del país como estado independiente. Desde los primeros meses de la Restauración en adelante, los panfletistas y cronistas portugueses reescribieron selectivamente la historia del período presentándolo como una época de cautividad babilónica; una lamentable pero breve aberración dentro de una gloriosa trayectoria nacional.

El hecho de que la separación de España pueda considerarse como un acontecimiento revolucionario en el ámbito histórico tanto portugués como europeo, aunque se llegase a ella a través de un golpe de estado y no de una verdadera revolución, complica aún más el problema de escribir acerca de la Unión de las Coronas. Los historiadores de la revolución buscan, de forma natural, indicadores que puedan explicar las causas de tales movimientos en la historia de las décadas precedentes. Al identificar las causas una a una, el hilo conductor se convierte en un relato autojustificado. En el caso de Portugal, esto quiere decir que el camino que conducirá a los sucesos del 1 de diciembre de 1640 había quedado ya abierto en el mismo momento en el que Felipe II de España tomaba juramento como Filipe I de Portugal en abril de 1581. Nos encontramos ante un pueblo alienado de España desde el principio; un monarca extranjero y ausente; una serie de promesas rotas; la pérdida de preciadas posesiones en ultramar; una creciente presión tributaria; un clero nacionalista y una nobleza cada vez más descontenta... Todos estos elementos propiciaban un espectacular divorcio al final de un matrimonio fallido. 
Es muy difícil, incluso para el historiador más avezado, romper con esta descripción teleológica de los acontecimientos ${ }^{2}$. Conociendo, como conocemos, el final de la historia, miramos hacia el pasado como si éste final hubiese sido inevitable. Debemos, sin embargo, y en la medida de lo posible, olvidar lo que ya sabemos y seguir el curso de los acontecimientos como si no conociésemos su resultado. A pesar de la imposibilidad del ejercicio, haré el esfuerzo en este artículo, centrándome primero en la naturaleza de la incorporación de Portugal a la Monarquía Hispánica compuesta, y considerando en segundo lugar las ventajas y desventajas que la Unión supuso para las partes implicadas. Concluiré después con algunas observaciones sobre las razones por las que se recuperó la independencia y sobre la permanencia de ésta.

Si echamos un vistazo al tipo de unión que representó la incorporación del reino de Portugal a la Monarquía Hispánica, descubriremos que se distinguió de uniones anteriores de tres maneras importantes al menos. Olivares, refiriéndose a las distintas formas de unión de reinos en su Gran Memorial de 1624, hizo la siguiente observación:

«V. Majd., y todos los otros reyes y príncipes soberanos, poseen sus estados por tres títulos: sucesión, conquista o elección...Todos cuanto V. Majd. posee hoy, menos algunas pequeñas partes de que no parece necesario hacer mención, los posee V. Majd. por derecho sucesivo: sólo son conquistas el reino de Navarra y el imperio de las Indias" ${ }^{3}$.

Este argumento no podía ser más claro: los derechos del rey sobre Portugal se basaban en derechos de herencia, como los del resto de los reinos de la Monarquía a excepción de Navarra y de las Indias. El Nicandro, sin embargo, escrito en defensa del Conde-Duque en 1643, culpaba a Felipe II por haber permitido que el duque de Braganza siguiera residiendo en Portugal, «que nunca varones de tan alto linaje y con pretensiones de rey se han de dejar en provincias conquistadas» 4 . En otras palabras, Portugal pertenecía al rey según el mismo derecho por el que éste poseía Navarra, es decir, el derecho de conquista. ¿Cuál de estas dos reivindicaciones era la correcta? Naturalmente, la respuesta es que cualquiera de las dos podían ser correctas, dependiendo de lo que uno quisiese creer en un momento dado. Felipe II había heredado Portugal, pero también lo había conquistado. Esta ambivalencia jurídica planeó desde el principio sobre la cuestión del estatus exacto de Portugal dentro de la monarquía compuesta. De esta forma quedaba marcada una diferencia entre esta unión y aquella de la mayoría de las partes componentes de la monarquía. Ni los ministros en Madrid, ni los portugueses podían olvidar que el duque de Alba había entrado en Portugal al frente de un ejérci-

2 Observaciones similares sobre los peligros y deficiencias del enfoque teleológico en relación con la recuperación de la independencia portuguesa pueden verse en BOUZA ÁLVAREZ, 1987, $209 / 12$. CARDIM, 2004, 369/70.

3 ELLIOTT y LA PEÑA, 1978, 1, 93.

4 Ibid., 2, 252. 
to conquistador ${ }^{5}$. El alcance de la influencia que este recuerdo pudo haber tenido en actitudes y comportamientos a ambos lados de la frontera es una cuestión que no se ha establecido aún de forma clara, pero que ha de tenerse en cuenta a la hora de evaluar la fortaleza y durabilidad de la Unión.

Al mismo tiempo, aunque una lectura de los acontecimientos que tuvieron lugar en Portugal en 1580 podría hacernos suponer que el reino fue conquistado, los términos de su incorporación, especificados en las Cortes de Tomar del año siguiente, seguían muy de cerca a los términos bajo los que se habían incorporado tradicionalmente los reinos heredados dentro de la Monarquía. Con anterioridad, el mismo rey ya había dejado claro que comprendía lo que esto implicaba al ordenar a sus ministros que pusieran de ejemplo la unión de las coronas de Castilla y Aragón con el fin de convencer a los portugueses de que la nueva situación no suponía la subordinación de su reino al de Castilla: «quel juntarse los unos reynos y los otros no se consigue por ser de un mysmo dueño, pues aunque lo son los de Aragón y éstos, sino tan apartados como lo heran quando heran de dueños diferentes " ${ }^{6}$. En otras palabras, el reino de Portugal había de ser tratado como si su adquisición se hubiese llevado a cabo por herencia, y no por conquista.

En Tomar, el rey dio muestras de sus buenas intenciones cuando consintió en una unión cuyas condiciones, en la práctica, favorecían más a la parte débil que aquellas negociadas entre los Reyes Católicos para la unión castellano-aragonesa. Felipe II aceptó íntegramente los artículos otorgados a los portugueses por don Manuel en 1499, cuando parecía que el hijo recién nacido de Manuel, Miguel, se convertiría algún día en rey de toda España. Estos artículos garantizaban que el reino mantendría sus instituciones existentes y que no se otorgaría ningún puesto en la Casa del Rey u otros cargos del reino a ningún extranjero ${ }^{7}$. Si bien Felipe II dio forma a la Unión tomando como modelo las uniones previas que habían dado lugar a la creación de la monarquía compuesta en España, el rey fue más allá de los acuerdos concebidos por los Reyes Católicos al abolir los puertos secos establecidos en 1559 entre Castilla y Portugal «en beneficio del pueblo y universal de estos reinos y porque se aumente el comercio y buena correspondencia.» Al final, sin embargo, esta relajación de las restricciones comerciales no duraría más de doce años ${ }^{8}$.

Las circunstancias de la incorporación de Portugal a la Monarquía Hispánica no sólo fueron poco usuales al tratarse de un reino que había sido conquistado y heredado al mismo tiempo (por mucho que se tratase de disfrazar la desnudez de la conquista con ropajes hereditarios), sino que además estas circunstancias no tenían precedentes, pues se unían no sólo dos coronas, sino también dos imperios. Por lo tanto, este hecho debía tenerse en cuenta a la hora de negociar las

\footnotetext{
5 Sobre la conquista y su influencia posterior véase VALLADARES, 2008.

6 Citado en BOUZA ÁLVAREZ 1987, 1, 341 y en PÉREZ SAMPER, 1992, 35.

7 BOUZA ÁLVAREZ, 1987, 1, 231/5.

8 ULLOA, 1977, 259.
} 
condiciones de la unión. Esto se logró, en primer lugar, a través de la regia promesa de defender no sólo Portugal, sino también sus posesiones de ultramar, promesa orientada a atraer a un reino destrozado por la derrota y pérdida de vidas de Alcázarquivir y dolorosamente consciente de la necesidad de asistencia externa para mantener sus extensas y lejanas posesiones en África, Asia y América. En segundo lugar, y de manera significativa, mientras que siempre rodeó cierta ambigüedad al derecho a establecerse en el Nuevo Mundo de los súbditos de la Corona de Aragón, a los naturales de Portugal se les permitió entrar con bastante flexibilidad, no sólo en Castilla, sino también en el imperio castellano de las Indias, concesión de la que sacarían el máximo provecho ${ }^{9}$. Éste fue un hecho sorprendentemente generoso, si tenemos en cuenta la determinación de la corona de enmarcar su imperio americano dentro de un ámbito exclusivamente castellano y la promesa de mantener, al mismo tiempo, el imperio ultramarino de Portugal en manos portuguesas. Esto sin duda refleja el reconocimiento por parte de la corona de la importancia de los mercaderes portugueses en la economía atlántica de España, especialmente en lo relacionado con la conservación del comercio esclavista transatlántico.

Si bien la Unión tomó forma según una unión dinástica tradicional, siguiendo líneas convencionales para la unión de entidades políticas distintas, al mismo tiempo tuvo lugar en circunstancias dinásticas poco usuales. La casa reinante nativa de Portugal se había extinguido a la muerte del cardenal Enrique, ¿o quizás no había sido así? Sobre la sucesión de Felipe II al trono planeó una duda inquietante, puesto que no sólo se daba la circunstancia de que el prior de Crato había reclamado sus derechos al trono (ellos mismos cuestionables), sino que, además, no había absoluta certeza con respecto a lo que verdaderamente había ocurrido con el rey Sebastián en Alcázarquivir. El reciente estudio de Ruth MacKay sobre los esfuerzos del pastelero Gabriel de Espinosa para hacerse pasar por el rey desaparecido pone de manifiesto el alcance de la preocupación de Felipe II, reflejada ésta en el grado de atención personal que el rey prestó hasta a los detalles más nimios del asunto, mientras los ministros reales trataban de desentrañar el misterio e identificar a los conspiradores detrás del mismo ${ }^{10}$.

La preocupación del rey es comprensible. El mundo de finales del siglo dieciséis era un mundo de profecías y rumores, lo que implicaba la necesidad de tomarse estos misterios en serio y poner freno a las murmuraciones antes de que se fueran de las manos. Además, el conocimiento de lo que tendía a ocurrir cuando el gobierno monárquico se ejercía desde lejos suponía que esta necesidad se hiciese aún más palpable. El absentismo regio era un factor natural asociado a la incorporación dentro de una monarquía compuesta, además de una fuente constante de descontento a lo largo y ancho de la Monarquía. El hecho de que su propia dinastía se hubiese extinguido tan recientemente suponía que la posibilidad

9 BOUZA ÁLVAREZ, 1987, 1, 641/6.

10 MACKAY, 2012. 
de ser regidos por un monarca extranjero no fuese bienvenida por los portugueses. Felipe trató de mitigar los efectos de su regreso a Madrid lo mejor que pudo a través de medidas como la conservación de la Casa del Rey portuguesa y la distribución de mercedes a la nobleza. Otras medidas que apuntaban en la misma dirección fueron la creación de un Consejo de Portugal y la promesa de que el reino sería regido, cuando el rey estuviese ausente, por una persona de sangre real o por virreyes o gobernadores naturales de Portugal. A través de estos recursos, sin embargo, sólo podía obtenerse un éxito parcial. La partida de Felipe dejó un vacío psicológico en el corazón del cuerpo político portugués que el fenómeno del sebastianismo buscaba rellenar.

La Unión de las Coronas constituyó, al menos en su intención, una relación contractual en la que las dos partes contratantes aunaban fuerzas para beneficiarse mutuamente al mismo tiempo que conservaban sus identidades distintivas. $\mathrm{Si}$ consideramos las ventajas y desventajas que la unión traía consigo o podía traer consigo para las dos partes, a primera vista podríamos concluir que ambas tenían mucho que ganar. Por supuesto, la unión había logrado hacer realidad el sueño inmemorial, ambicionado por las casas reinantes tanto de España como de Portugal, de restaurar la Hispania romana y visigoda; el sueño de la península unida bajo un único monarca. Al unir bajo su cetro no sólo dos reinos, sino también dos imperios, se reforzaba y se consolidaba el carácter global de la monarquía y parecían confirmarse las promesas de fray Hernando del Castillo al rey cuando le aseguraba, en 1579, que «uniendo el reyno de Portugal al de Castilla será el mayor Rey del mundo» ${ }^{11}$. Con la adquisición de Portugal se cubría el flanco occidental, que era el flanco más vulnerable de Felipe, dándole acceso a Lisboa y a otros puertos a lo largo de la costa atlántica portuguesa. Al mismo tiempo, el rey obtenía un impresionante acrecentamiento de sus fuerzas navales en la forma de astilleros, marinos con experiencia, una gran flota mercante y doce galeones de guerra ${ }^{12}$. Lisboa estaba situada en un emplazamiento ideal para servir al mismo tiempo de puesto de vigilancia y de base de operaciones en un momento en el que la lucha contra las fuerzas protestantes del norte se recrudecía y apuntaba cada vez más a que su resultado se decidiría en las aguas del Atlántico.

La adquisición de Portugal también dio acceso a Felipe al comercio de especias de las Indias Orientales, a los mercaderes esclavistas del África portuguesa y a los servicios comerciales y financieros de la comunidad mercantil portuguesa. Muchos de los miembros de ésta eran conversos o cripto-judíos deseosos de aprovechar las posibilidades lucrativas que la Unión ofrecía. La Monarquía Hispánica dominaba ahora las rutas comerciales del mundo y disponía de una gran parte de los recursos mundiales de metales preciosos para la acuñación de moneda: el oro de Guinea y la plata de América. Además, disfrutaba del monopolio virtual del suministro de sal mundial y poseía, en Lisboa, el emporio europeo de las

11 Citado por BOUZA ÁLVAREZ, 1987 1, 82.

12 ELLIOTT, 1991, 53. 
especias asiáticas y del azúcar brasileño. Todo esto otorgaba a la Monarquía, al menos potencialmente, una enorme ventaja económica ${ }^{13}$.

Desde el punto de vista de los portugueses, que vivían momentos de aguda crisis social y económica, su incorporación a la monarquía de Felipe parecía actuar como un oportuno salvavidas. La nobleza deseaba buscar empleo en sus dominios alrededor del mundo y se tenía la expectativa general de que el poder militar y naval de España serviría para defender de forma efectiva, como Felipe había prometido, el imperio del reino en ultramar. Esta expectativa no era poco razonable, pero se vería frustrada porque una monarquía sobreextendida no podía defender todos y cada uno de los destacamentos vulnerables de la monarquía alrededor del globo frente a los ataques de potentados locales y enemigos europeos. A pesar de que los españoles despacharon una serie de fuerzas expedicionarias desde Manila a las Molucas, fueron incapaces de retomar Ternate ${ }^{14}$, y poco a poco el imperio asiático de Portugal se fue erosionando. Mendo da Mota observó, en un análisis pesimista de las causas que movían a los descontentos portugueses, que una de las mayores quejas de éstos era que «no se tiene cuenta con su defensión: que están expuestos a los enemigos de Castilla, sin darles ningún socorro; que tienen por ésto perdidos sus comercios, la Mina, y gran parte de la India» 15 .

Uno se ve obligado a preguntarse hasta qué punto era justa esta crítica. Los portugueses aducían que los embargos españoles al tráfico marítimo holandés e inglés en los puertos ibéricos, empezando por el de 1585, habían involucrado a su reino en guerras que no habían sido comenzadas por ellos. En cierto modo, los embargos habían sido demasiado efectivos como armas en la guerra contra los rebeldes y los protestantes puesto que, al cerrarles la puerta de los recursos europeos para el suministro de artículos extraeuropeos, los holandeses se habían visto forzados a expandir sus actividades comerciales en ultramar. De 1599 en adelante hubo un incremento masivo en el número de embarcaciones holandesas que navegaban al Caribe, al África Occidental y a las Indias Orientales ${ }^{16}$. Durante las siguientes dos décadas, los holandeses descubrieron que era posible adquirir productos extraeuropeos directamente de la fuente y, de esta forma, el imperio portugués de ultramar se convirtió en un objetivo de ataque directo. Nos encontramos ante un ejemplo clásico de la ley de consecuencias imprevistas. Sin embargo, llegar a saber si, a la larga, un Portugal independiente hubiese podido evitar las incursiones anglo-holandesas en sus territorios continúa siendo una cuestión sin resolver. Hacía tiempo que los ingleses cuestionaban las reivindicaciones de Portugal sobre el derecho al monopolio del comercio en Guinea. Además, resulta difícil imaginar que los ingleses o los holandeses hubiesen estado dispuestos a

\footnotetext{
13 Véanse SCHWARTZ, 1992, 205/26, e ISRAEL, 1990, 189.

14 NEWLITT, 2005, 196.

15 British Library, Egerton Ms. 1133, fs. 270/275, Memorial de Mendo de Mota (sin fecha).

16 Véase ISRAEL, 1990, 199/200.
} 
aceptar la posesión perpetua, por parte de los portugueses, del derecho exclusivo al comercio marítimo más allá del Cabo de Buena Esperanza ${ }^{17}$.

Por lo tanto, a finales del reinado de Felipe III quedaba claro que la Unión había defraudado las expectativas portuguesas en lo tocante a la protección de su imperio de ultramar, aunque es posible que estas expectativas, desde el principio, hubiesen apuntado demasiado alto. Al menos en teoría, el gobierno de Madrid estaba comprometido, y seguiría estándolo, con la defensa del imperio de Portugal, y durante las décadas de 1620 y 1630, la expulsión de los holandeses del Brasil sería un asunto de máxima prioridad para el régimen de Olivares. En particular, la expedición conjunta hispano-portuguesa que retomó Bahía en 1625 es un ejemplo clásico del tipo de cooperación prevista en 1580 y 1581. Al mismo tiempo, ejemplifica también a la perfección la unión de armas y de almas que el CondeDuque percibía como esencial no sólo para dar mayor sentido a la Unión de las Coronas, sino también para asegurar la supervivencia de la Monarquía compuesta de España en su conjunto ${ }^{18}$.

Si bien es cierto que holandeses e ingleses hicieron gran daño a los intereses territoriales y comerciales de Portugal tras la Unión, sería un error subestimar las ventajas económicas que la misma conllevaba para ambas partes. En todo acuerdo político y constitucional de gran alcance como el que se concertó entre España y Portugal, siempre habrá ganadores y perdedores. Entre los principales beneficiados se encontraron, de forma notoria, un grupo de mercaderes portugueses, muchos de ellos conversos y algunos cripto-judíos, que aprovecharon la oportunidad de introducirse en la economía atlántica española para después usar sus ganancias como un trampolín con el que obtener un mayor control sobre importantes áreas de la vida comercial y del sistema tributario de Castilla.

Los contornos de la historia son bien conocidos. Comienza ésta con la negociación de contratos exclusivos con la corona española para la provisión de esclavos africanos en el imperio de las Indias y culmina con la revolución financiera de 1627, cuando el Conde-Duque recurrió a hombres de negocios portugueses para romper con el control genovés sobre la hacienda real ${ }^{19}$. Es posible perder de vista que lo que está sucediendo en este período es un intento por parte de la comunidad mercantil portuguesa, no sólo de forzar su entrada en el imperio español de Indias y desempeñar un papel activo en la financiación de la corona española, sino también de cambiar algunos de los principios fundamentales que tradicionalmente habían regido la toma de decisiones en Madrid. Disfrutando ellos mismos de estrechos contactos con mercaderes holandeses y de otras zonas del norte de Europa, los mercaderes portugueses deseaban apartar a la corona de su recurso típico ante los problemas, que era la guerra, para dar mayor protagonismo

17 BOXER, 1969, 108/9.

18 Véase SCHWARTZ, 96 (Bloomington, 1991): 735/62.

19 Véanse especialmente: VILA VILAR, 1977. BOYAJIAN, 1983. STUDNICKI-GIZBERT, 2007. 
a las consideraciones económicas en el proceso de formulación de políticas. Una forma de lograr esto conllevaba que, a la hora de buscar consejo, la Corona tuviese en cuenta a los hombres de negocios. Los beneficios de este proceder podían ser inmensos pues, como Duarte Gómez Solís apuntaba en sus Discursos sobre los comercios de las dos Indias de 1622, «el comercio y la contratación es más poderosa que las armas... y no ay fortaleza tan fuerte, a quien la pólbora del dinero no contramine» 20 .

En Olivares encontraron un público receptivo. He aquí un gobernante que se había dado cuenta de la importancia del comercio y de la industria y que en su Gran Memorial insistiría en la necesidad de «gobernar por compañías y consulados la mercancía de España, poniendo el hombro en reducir los españoles a mercaderes» 21 . Al recurrir a hombres de negocios portugueses para que ayudaran con las finanzas de la Corona y al colmarles de mercedes en recompensa por sus esfuerzos, a los últimos debió parecerles por un momento que su sueño de poder no sólo influir, sino también redefinir la toma de decisiones en Madrid, estaba a punto de cumplirse. Lisboa, con su habilidad para los asuntos económicos, tendría por fin una voz representativa en Madrid. Sin embargo las cosas al final no salieron como ellos habrían deseado. Sus intentos de reformular el funcionamiento de la economía atlántica española fracasaron. Los intereses creados en la carrera de Indias eran demasiado fuertes, y los consulados de Sevilla, Méjico y Lima estaban resueltos a impedir cualquier limitación de sus preciados derechos sobre el monopolio. No sólo se organizaron poderosas fuerzas contra los asentistas portugueses, sino que su codicia y ostentación, además de la sospecha de judaísmo que pendía sobre ellos, les hicieron peligrosamente vulnerables ante los ataques de quienes se sentían ofendidos por su presencia en la corte y querían acabar con el valimiento del Conde-Duque. Sus supuestas acciones judaizantes, su connivencia con mercaderes de países enemigos y sus actividades comerciales clandestinas en el mundo atlántico español provocaron una reacción violenta dentro de la Monarquía. Se activaron los autos de fe y, tras la revuelta de 1640 y la caída de Olivares, su momento ya había pasado ${ }^{22}$.

Sin embargo, las habilidades empresariales, comerciales y financieras de los portugueses proporcionaron energía y vitalidad renovadas a la Monarquía durante los sesenta años que duró la unión hispano-portuguesa. El papel desempeñado por la comunidad mercantil portuguesa en el desarrollo de las plantaciones de azúcar brasileñas tuvo como consecuencia la entrada de nueva riqueza en la península ibérica y, por extensión, en las arcas reales. Para el mismo reino de Portugal, el período de la Unión de las Coronas fue una época de estabilidad monetaria, gracias a las especias asiáticas, al azúcar de Brasil y a las grandes cantidades

20 GOMES, 1943, 41/3.

21 ELLIOTT y LA PEÑA, 1978, 1, 98.

22 Sobre las esperanzas y decepciones de la comunidad mercante portuguesa véanse STUDNICKIGIZBERT, 2007, 160/3, y (Columbia, 2005): 152/85. 
de plata adquiridas a través tanto de la participación legal en el comercio atlántico, como del contrabando de plata por tierra desde Potosí a Buenos Aires, de donde se enviaba clandestinamente a Lisboa. Esta situación se encontraba en claro contraste con la volatilidad de la moneda castellana durante estos mismos años, cuando la estabilidad de la misma se vio debilitada por el recurso cada vez más frecuente de la acuñación de vellón ${ }^{23}$. Por lo tanto, la incorporación de Portugal en la Monarquía trajo consigo tanto beneficios económicos como pérdidas. Si bien puede responsabilizarse a la Unión, al menos parcialmente, por la pérdida de parte del imperio asiático de Portugal, también es cierto que este hecho se vio compensado por la inclusión del reino, a caballo entre la legalidad y la ilegalidad, en la economía, rica en plata, del atlántico español.

Además de en los aspectos estrictamente económicos, Portugal también pudo beneficiarse de la Unión de otras maneras. Los cambios judiciales y administrativos puestos en marcha por Felipe II, como la compilación de las Ordenanzas Filipinas o la creación de un conselho da fazenda y de un conselho da Índia según el modelo de consejos español, contribuyeron a renovar la anticuada maquinaria de justicia y gobierno del reino ${ }^{24}$. Por otro lado, sin embargo, las decisiones de guerra y paz se tomaban ahora en la lejana Madrid y, sin rey ni corte, el acceso a la persona del monarca resultaba incomparablemente más difícil. La distancia, por tanto, creaba retrasos, y las oportunidades de corrupción se multiplicaban mientras que las peticiones eran tramitadas a través de intermediarios y los letrados crecían en poder e influencia a expensas de la antigua nobleza. Se produjeron también problemas interminables en torno a la forma que debía tomar el gobierno absentista del rey mientras la Corona decidía si lo más conveniente para el gobierno del reino era una persona de sangre real, un virrey único o varios gobernadores.

Al analizar estos problemas, convendría prestar mayor atención a los cambios en el uso de la palabra provincia; palabra que es, a mi juicio, clave dentro del léxico político del siglo diecisiete. Los catalanes de principios de dicho siglo parecen haber descrito su principado de forma intercambiable como nació, patria o provincia, siendo éste último término aparentemente neutral y desprovisto de cualquier tinte que implicase subordinación ${ }^{25}$. Covarrubias define provincia como «una parte de tierra estendida, que antiguamente acerca de los romanos eran las regiones conquistadas fuera de Italia» ${ }^{26}$. Cuando los portugueses protestaron en 1600 contra el nombramiento de Cristóbal de Moura, que no era de sangre real pero sí portugués, como virrey, recurrieron a esta segunda acepción romana de la palabra provincia, que hace referencia a un territorio conquistado. Según una carta del

23 MAURO, 1960, 417-21.

24 Sobre los sistemas administrativo y judicial durante el período de la Unión de las Coronas véanse HESPANHA, 1989 y SCHAUB, 2001.

25 ELLIOTT, 1977, 43.

26 COVARRUBIAS, 1943, 885. 
conde de Portalegre, «quanto al reyno con la provisión de uno solo que no es príncipe se redujo en provincia y se facilita la entrada de los forasteros prohibida en las capitulaciones de las gracias otorgadas " ${ }^{27}$. El miedo a ser gobernado por extranjeros como consecuencia del absentismo real era común a cualquier monarquía compuesta, pero, además, en este caso, desembocó en el empleo de la acepción romana de provincia. Los portugueses no podían ignorar el hecho de que su reino y patria había sucumbido ante la conquista extranjera.

El perturbador sentimiento de que Portugal había caído en manos de extranjeros enturbió la respuesta portuguesa a la Unión de las Coronas, pero esto no implica necesariamente que la Unión estuviese condenada desde el principio. Es cierto que la incorporación a la Monarquía Española produjo pérdidas para algunos, pero también creó nuevas oportunidades para otros. ¿Habría conseguido Velázquez, que según parece provenía de una familia de conversos portugue$\operatorname{ses}^{28}$, disfrutar de una carrera tan brillante si solamente hubiese sido el pintor del rey de un Portugal independiente y no el del monarca más poderoso de la Cristiandad? No debemos apresurarnos a descartar las posibilidades que entrañaba la Unión, pues permitió el despegue de algunos portugueses. Las órdenes religiosas de España y Portugal, aunque a menudo en conflicto entre sí, se consideraban implicadas las unas con las otras en una empresa común, que era la de promover la Cristiandad a nivel mundial bajo los auspicios de una monarquía global. Al mismo tiempo, las familias aristocráticas de España y Portugal venían casándose entre sí incluso antes de la Unión, y la carrera política de Diego de Silva y Mendoza, conde de Salinas, auguraba para la descendencia de estos matrimonios un futuro transnacional al servicio de la Corona española ${ }^{29}$. Mientras tanto, cada vez se publicaban más obras de autores portugueses en castellano y las comedias castellanas, que gozaban de una creciente popularidad en el teatro portugués, comenzaron a incorporar temas portugueses a sus argumentos $^{30}$. La lengua no era todavía el indicador definitivo de identidad nacional que llegaría a ser más tarde y las delimitaciones de la nacionalidad en la Europa del siglo diecisiete no estaban aún claramente dibujadas. Debidamente manejados, el tiempo y un conocimiento mutuo más profundo podrían haber limado asperezas.

Al final esto no ocurrió. El Conde-Duque, igual que Jacobo VI de Escocia al convertirse en rey de Inglaterra, veía con claridad la necesidad de formar una unión de mente y espíritu para poder llevar a cabo una verdadera unión de reinos. Sin embargo, como ambos descubrirían, esto no era algo que pudiese hacerse de la noche a la mañana, y las decisiones políticas del Conde-Duque, determinadas por necesidades de mayor urgencia, socavaron el mismo proceso que él conside-

27 BOUZA ÁLVAREZ, 1991, 137.

28 INGRAM (Madrid, 1999): 69/85.

29 Véanse GAILLARD, 1983 y DADSON, 2011.

30 PÉREZ SAMPER, 1992, 48. 
raba esencial para alcanzar el éxito. Mientras la guerra regresaba al norte y al centro de Europa en los años posteriores a 1621, el clima político comenzó a deteriorarse no sólo en cuanto a la relación entre España y Portugal, sino también en el conjunto de la Monarquía Hispánica a raíz de las presiones surgidas por la movilización de hombres y dinero, que se multiplicaban e imponían nuevas tensiones en uniones aún en formación.

Las reacciones a los intentos del gobierno de Madrid por mitigar la carga impositiva de Castilla a través de la equiparación de las contribuciones de otros reinos y provincias, produjeron respuestas similares en todas partes. La reacción de Portugal fue muy parecida a la de Cataluña. Las continuas demandas emanadas del gobierno central y su puesta en práctica a través de oficiales locales impopulares produjeron que una parte de la comunidad tras otra se sintiesen distanciadas de la Corona y del régimen. El vacío resultante fue rellenado con un creciente sentimiento de la patria percibida como una entidad por derecho propio y no como un sistema gubernamental en el que rey y pueblo cooperaban en base a ciertas obligaciones mutuas. Tanto en Cataluña como en Portugal, los derechos y libertades de la patria se consideraban amenazados por los ministros y oficiales de un monarca distante que no comprendía sus problemas. Como es bien sabido, Quevedo escribió en respuesta a la rebelión de Cataluña que «el tema de los de Barcelona... es el refrán que dice: "No es por el güevo, sino por el fuero"». En una carta escrita por el Conde-Duque tras el motín de Évora de 1637 en la que comentaba que la causa de los incidentes había sido la imposición del real de agua, el valido apostilló: «pero no está en esto el punto sino en que no es por el güevo sino por el fuero... ${ }^{31}$. Cualquiera que fuese la relación exacta entre huevo y fuero, en ambos casos el fuero era parte integral de la ecuación.

La rebelión que tuvo lugar en Portugal a partir de diciembre de 1640 se vio al mismo tiempo precipitada y posibilitada por la precedente rebelión de Cataluña y la resultante visibilidad del debilitamiento de la Corona española. Saber si, de otra forma, la rebelión hubiese llegado a tener lugar o si hubiese ocurrido de la manera en que lo hizo es una pregunta abierta a debate. Las disensiones en el seno de la élite portuguesa en los meses y años siguientes sugieren que, en otras circunstancias, la restauración de la independencia habría estado lejos de ser la conclusión obvia del conflicto. Merece la pena, sin embargo, considerar por un momento por qué Portugal, al contrario que Cataluña, logró separarse permanentemente de la Monarquía Hispánica ${ }^{32}$.

Una diferencia significativa estriba en el hecho de que Portugal era un reino, mientras que Cataluña no lo era. Aunque fuese ya demasiado tarde para que el

31 QUEVEDO, 1966, 937/938 («La Rebelión de Barcelona»).VIÑAS NAVARRO, VII (Madrid, 1925): 49. Véase también la cita del mismo refrán en una carta del Conde-Duque al conde de Basto del 18 de diciembre de 1637 en VALLADARES, 1998, 154.

32 Véanse más consideraciones sobre las similitudes y diferencias entre Portugal y Cataluña en ELLIOTT, 1977, 478/481, y PÉREZ SAMPER, 1992, cap. III. 
rey Sebastián volviese y reclamase su legítima herencia, Portugal al menos tenía un potencial rey de reserva en la persona del duque de Braganza, vástago de una rama del antiguo linaje real. En la Europa abrumadoramente monárquica del siglo diecisiete, que recelaba de las repúblicas, la proclamación del duque como rey de un Portugal independiente otorgaba a la rebelión portuguesa un grado de respetabilidad y legitimidad internacional al que los catalanes no podían aspirar. Al mismo tiempo, el simple hecho de que la unión con España fuese tan reciente tenía como consecuencia que la proclamación del nuevo rey resultase mucho más convincente. Al fin y al cabo, el reino de Portugal había sido gobernado por reyes propios desde tiempos inmemoriales. Sin embargo, era mucho más importante a largo plazo el hecho de que Portugal poseía un imperio de ultramar que, a pesar de haberse visto reducido en algunas de sus posesiones en los últimos sesenta años, seguía siendo una importante fuente de riqueza. Este imperio podía llegar a ser aún más rico si las plantaciones de azúcar del Brasil pudiesen ser tomadas de nuevo de manos de los holandeses. Por todo esto, su supervivencia como reino independiente suscitaba gran interés entre los rivales de España. Los mismos holandeses, los franceses y, a su debido tiempo, los ingleses; todos eran conscientes de las oportunidades comerciales que podían presentarse para ellos si ofrecían su apoyo al nuevo régimen portugués. En comparación, ¿qué ventajas podían derivarse de la asistencia a los catalanes más allá de minar el poder español? Hacía tiempo que el principado había perdido su imperio mediterráneo y, si bien el Mediterráneo del diecisiete no puede considerarse de ninguna manera una zona estancada, carecía del atractivo que sí poseían el mundo atlántico y su potencial prácticamente ilimitado.

Sin embargo, una vez más debemos ser cuidadosos de no analizar retrospectivamente el curso de los acontecimientos. Si hubiese sido Francia y no España la que sucumbiera bajo el peso del conflicto de 1639-1640, o incluso si el ejército del marqués de Los Vélez hubiese resultado victorioso en la batalla de Montjuïc, hoy podríamos estar escribiendo una historia bien distinta, una en la que Portugal podría haberse convertido, con el tiempo, en una parte mucho más integrada de la Monarquía Hispánica. Al fin y al cabo, esa era la Monarquía que había concebido el Conde-Duque; una Monarquía en la que uniones que eran meramente formales se consolidaban a través de cooperación mutua y lazos de afecto $^{33}$. Esto fue demasiado pedir y resultó ser el camino desechado. Sería el nacionalismo, y no el transnacionalismo, el que durante los tres siglos siguientes estaría a la orden del día.

${ }^{33}$ Véase FERNÁNDEZ ALBALADEJO, 2009, 73/81. 


\section{BIBLIOGRAFÍA}

BOUZA ÁLVAREZ, Fernando J., «La «soledad» de los reinos y la «semejanza del rey». Los virreinatos de príncipes en el Portugal de los Felipes», en Massimo Ganci y Ruggiero Romano (coords.), Governare il Mondo. L'Impero Spagnolo dal XV al XIX Secolo, Palermo, Instituto di Storia Moderna, 1991: 125/139.

- Portugal en la Monarquía Hispánica, 1580-1640, 2 vols., Madrid, Universidad Complutense, 1987.

BOXER, Charles R., The Portuguese Seaborne Empire, 1415-1825, Londres, Hutchinson, 1969.

BOYAJIAN, James C., Portuguese Bankers at the Court of Spain, 1626-1650, New Brunswick, Rutgers University Press, 1983.

CARDIM, Pedro, «Los Portugueses frente a la Monarquía Hispánica», en Antonio Álvarez Ossorio Alvariño y Bernardo J. García García (coords.), La monarquía de las naciones, Madrid, Fundación Carlos de Amberes, 2004: 355/383.

COVARRUBIAS, Sebastián de, Tesoro de la lengua castellana o española (1611), Martín de Riquer (ed.), Barcelona, Horta, 1943.

DADSON, Trevor J., Diego de Silva y Mendoza. Poeta y político en la corte de Felipe III, Granada, Universidad de Granada, 2011.

ELLIOTT, John H. y LA PEÑA, José F. de, Memoriales y cartas del Conde Duque de Olivares, 2 vols., Madrid, Alfaguara, 1978-81.

- «The Spanish Monarchy and the Kingdom of Portugal, 1580-1640», en Mark Greengrass (ed.), Conquest and Coalescence. The Shaping of the State in Early Modern Europe, Londres, Edward Arnold, 1991: 48/67.

- La rebelión de los catalanes, 1598-1640, Madrid, Siglo XXI, 1977.

FERNÁNDEZ ALBALADEJO, Pablo, "Common Souls, Autonomous Bodies: the Language of Unification Under the Catholic Monarchy, 1590-1630", en Jon Arrieta y John H. Elliott (coord.), Forms of Union: the British and Spanish Monarchies in the Seventeenth and Eighteenth Centuries (RIEV. Cuadernos; 5), Donostia, Eusko Ikaskuntza, 2009: 73-81.

GAILLARD, Claude, Le Portugal sous Philippe III d'Espagne. L'Action de Diego de Silva y Mendoza, Grenoble, Universidad de Grenoble, 1983.

GOMES, Duarte, Discursos sobre los comercios de las dos Indias, Moses Bensabat Amzalak (ed.), Lisboa, Anaís do Instituto Superior de Ciencias Economicas, 1943.

HESPANHA, António M., Vísperas del Leviatán. Instituciones y poder político, Portugal, siglo XVII, Madrid, Taurus, 1989.

INGRAM, Kenneth, «Diego Velázquez's Secret History», Boletín del Museo del Prado, XVII/35 (Madrid, 1999): 69/85.

ISRAEL, Jonathan I., Empires and Entrepots. The Dutch, the Spanish Monarchy and the Jews, 1585-1713, Londres y Ronceverte, The Hambledon Press, 1990.

MACKAY, Ruth, The Baker Who Pretended to Be King of Portugal, Chicago, Chicago University Press, 2012.

MAURO, Frédéric, Le Portugal et l'Atlantique au XVIIle Siècle, 1570-1670, Paris, S.E.V.P.E.N., 1960.

NEWLITT, Malyn, A History of Portuguese Overseas Expansion, 1400-1668, Londres, Routledge, 2005.

PÉREZ SAMPER, M. Àngels, Catalunya i Portugal, Barcelona, Curial, 1992.

QUEVEDO y VILLEGAS, Francisco de, Obras completas. Obras en prosa, Felicidad BUENDÍA (ed.), Madrid, Aguilar, 1966.

SCHAUB, Jean-Frédéric, Le Portugal au temps du Comte-Duc d'Olivares, 1621-1640, Madrid, Casa de Velázquez, 2001. 
SCHWARTZ, Stuart B., «Panic in the Indies: the Portuguese Threat to the Spanish Empire 16401650", in Werner Thomas y Bart De Roof (coords.), Rebelión y resistencia en el mundo hispánico del siglo XVII, Leuven, Leuven University Press, 1992: 205/26.

- «The Voyage of the Vassals: Royal Power, Noble Obligations, and Merchant Capital before the Portuguese Restoration of Independence, 1624-1640», The American Historical Review, 96 (Bloomington, 1991): 735/762.

STUDNICKI-GIZBERT, Daviken, «Revisiting 1640: or How the Party of Commercial Expansion Lost to the Party of Political Conservation in Spain's Atlantic Empire, 1620-1650", en Peter A. Coclanis (ed.), The Atlantic Economy During the Seventeenth and Eighteenth Centuries, Columbia, University of South Carolina Press, 2005:152/85.

STUDNICKI-GIZBERT, Daviken, A Nation Upon the Ocean Sea. Portugal's Atlantic Diaspora and the Crisis of the Spanish Empire, 1492-1640, Oxford, Oxford University Press, 2007.

ULLOA, Modesto, La hacienda real de Castilla en el reinado de Felipe II, Madrid, Fundación Universitaria Española, 1977.

VALLADARES, Rafael (ed.), Epistolario de Olivares y el Conde de Basto (Portugal 1637-1638), Bajadoz, Diputación de Badajoz, 1998.

VALLADARES, Rafael, La conquista de Lisboa. Violencia militar y comunidad política en Portugal, 1578-1583, Madrid, Marcial Pons, 2008.

VILA VILAR, Enriqueta, Hispano-América y el comercio de esclavos. Los asientos portugueses, Sevilla, Escuela de Estudios Hispanoamericanos, 1977.

VIÑAS NAVARRO, Aurelio, «El Motín de Évora y su significación en la restauración portuguesa de 1640", Boletín de la Biblioteca Menéndez y Pelayo, VII (1925): 321/39. 